\title{
Técnicas diagnósticas de infección humana por hantavirus
}

\author{
T.M. HECTOR GALENO A. ${ }^{1}$, ELIECER VILLAGRA C. ${ }^{1}$, B.Q. JORGE FERNANDEZ O. ${ }^{1}$, \\ B.Q. EUGENIO RAMIREZ V. ${ }^{1}$ y M.V.JUDITH MORA R. ${ }^{1}$
}

\section{DIAGNOSTIC TECHNIQUES FOR HANTAVIRUS HUMAN INFECTION}

Hantavirus are enveloped viruses with trisegmented RNA. American isolates belong to subfamily Sigmodontinae rodents and can cause hantavirus cardiopulmonary syndrome (HCPS) while European and Asiatic hantavirus belong to subfamilies Murinae and Arvicolinae and can produce hemorragic fever with renal syndrome. In this article the laboratory techniques employed at the present time to certify human hantavirus infection are described.

Key words: Hantavirus; Laboratory diagnosis; Serology; RT-PCR; Immunohistochemistry; Isolation.

\section{INTRODUCCION}

En Chile, la infección por hantavirus es una zoonosis endémica que ha generando casos humanos desde las VI a XI regiones. Mediante trampeo de roedores se ha observado la circulación de hantavirus en ratones capturados desde la Región Metropolitana hasta la XI Región. Hasta ahora se ha determinado la presencia de hantavirus en Oligoryzomys longicaudatus y en Abrothrix longipilis, existiendo especímenes serológicamente positivos de otras especies, pero en las cuales no se ha detectado la portación de virus.

Artículo relacionado de C. Pavletic B. en pág. 186

1 Instituto de Salud Pública de Chile, Sección Virología.
Desde su reconocimiento en Chile, a junio del 2000 se han notificado 119 casos de síndrome cardiopulmonar por hantavirus (SCPH), con una letalidad cercana a 50\%. Por otra parte, se han detectado casos de infección por hantavirus que no han cursado con SCPH, incluyendo casos de infección asintomática (Informe de Situación Epidemiológica de Hantavirus, Julio 2000, MINSAL). Por la frecuente presentación en conglomerados de casos relacionados y por otros antecedentes, no es posible descartar categóricamente la transmisión persona a persona en etapas tempranas de la infección. Este fenómeno parece ser propio de los hantavirus circulantes en Chile y Argentina. ${ }^{1-3}$ Un elemento importante para la sobrevida de los pacientes es la sospecha y el diagnóstico precoz de la infec- 
ción por hantavirus, lo que permite iniciar un manejo oportuno del caso, mejorando significativamente la sobrevida de estos pacientes. ${ }^{4}$ Además, facilita una rápida acción en el lugar probable de contagio de estos pacientes.

\section{Generalidades}

El género Hantavirus es uno de los 5 géneros de la familia Bunyaviridae. Este género es el único de la familia que no se transmite a través de artrópodos hematófagos. Los otros 4 géneros (Bunyavirus, Nairovirus, Phlebovirus y Tospovirus) constituyen los arbovirus (arthropod-borne viruses). La transmisión de los hantavirus desde los roedores al humano ocurre mediante la aerolización de orina, heces o saliva de roedores portadores crónicos del virus. ${ }^{5}$

Los hantavirus, al igual que los arbovirus, poseen genoma ARN trisegmentado: segmento $\mathrm{S}$ (short), segmento M (medium) y segmento L (large). El segmento S codifica para la nucleoproteína (o proteína del core viral), el segmento M codifica para las 2 proteínas de envoltura, el segmento L codifica para proteínas no estructurales (polimerasa viral). Desde el punto de vista morfológico, los hantavirus son de forma esférica u oval, de 70 a $120 \mathrm{~nm}$ de diámetro. El componente proteico mayor lo constituyen las moléculas de nucleoproteína que estructuran la nucleocápside y ésta contiene al ARN genómico en su interior. La nucleocápside está rodeada por la envoltura viral, conformada por una bicapa lipídica (suministrada por la célula huésped) y por las glicoproteínas de la envoltura viral (G1 y G2).

Dentro del género Hantavirus se han reconocido diferentes especies, cepas, serotipos, aislados o variantes (estas diferentes denominaciones pueden ser consideradas como sinónimos). Debido a las dificultades de manejo de estos virus, a la fecha no se ha podido establecer una clasificación exacta de ellos. Se ha aceptado el uso de la secuenciación de ácidos nucleicos para establecer las relaciones taxonómicas entre hantavirus circulantes en diferentes hábitats, aun partiendo de ácidos nucleicos virales recuperados directamente de tejidos o sangre. ${ }^{6}$ Sin embargo, diferencias genéticas no necesaria- mente significan diferencias estructurales o funcionales.

Desde el punto de vista evolutivo, los hantavirus parecen haberse adaptado a diferentes especies de roedores y juntos han coevolucionado. ${ }^{7}$ Los hantavirus americanos provienen de la subfamilia de roedores Sigmodontinae y pueden causar el síndrome cardiopulmonar por hantavirus (SCPH) mientras que los hantavirus europeos y asiáticos provienen de las subfamilias Murinae y Arvicolinae, que pueden producir la fiebre hemorrágica con síndrome renal (HFRS) ${ }^{8-11} \mathrm{~A}$ la fecha, no se conoce el o los factores virales que determinan la correspondiente manifestación clínica de los hantavirus provenientes de las diferentes subfamilias de roedores. La relevancia de los hantavirus americanos radica en la elevada letalidad observada (40-60\%). Los hantavirus americanos que más casos humanos han causado (casos notificados) son: el virus Sin Nombre (SNV) del ratón norteamericano Peromyscus maniculatus, y el virus Andes (AND) del ratón sudamericano Oligoryzomys longicaudatus. ${ }^{12-15}$

Un virus propio de una especie de roedor puede infectar a otras especies que compartan el mismo hábitat (fenómeno denominado spillover). Sin embargo, la infección en esta otra especie es autolimitada y no tiene mayor relevancia epidemiológica. Desde el punto de vista del laboratorio, es posible detectar anticuerpos anti hantavirus en esta especie secundaria, pero es poco probable la detección de virus o genoma viral. Esto no excluye que dos o más virus diferentes puedan circular en un mismo hábitat.

La infección en el ratón no parece tener mayores consecuencias para su huésped. Se puede detectar la presencia de virus tanto en sangre, muestras de diferentes órganos, así como en secreciones, orina y deposición del roedor infectado. En humanos, después de ocurrir una infección preliminar en células de la mucosa de las vías respiratorias, los virus pasan al torrente circulatorio, iniciando ciclos de multiplicación generalizada. Las células blanco de la infección son las células endoteliales de los vasos sanguí- 
neos. ${ }^{16}$ Mediante el análisis de necropsias se ha podido visualizar la presencia de proteínas o ácidos nucleicos virales en diferentes órganos, especialmente asociados al endotelio capilar. ${ }^{17}$,

${ }^{18}$ No se observa necrosis de tejido, se aprecia la presencia de inmunoblastos en mayor o menor cantidad. En la infección con hantavirus americanos es poco común observar microhemorragias; en el tejido pulmonar se observa la condensación de material proteináceo en los alvéolos, reflejando el paso de plasma hacia ese espacio. Al parecer, las células endoteliales infectadas sufren una alteración funcional que les impide mantener las uniones intercelulares, dejando poros que permiten el paso libre de plasma y generando consumo masivo de plaquetas. La recuperación de la permeabilidad selectiva normal de los vasos sanguíneos pasa por el recambio de las células pero también impidiendo la infección de nuevas células endoteliales. Parece ser que la respuesta inmune juega un rol importante en la superación de la infección a través de la producción de anticuerpos neutralizantes. Los pacientes que logran recuperarse de esta infección no muestran mayores señales de secuelas macro o microscópicas del proceso.

Para explicar las diferencias en la expresión de la infección por hantavirus en diferentes individuos hay que tener presente: la variante funcional viral, la dosis infectante y la rapidez de la generación de anticuerpos neutralizantes, entre otros factores. En nuestro medio, además del síndrome clásico, podemos observar personas que cursan la infección sin manifestar síntomas, o personas que presentan síntomas sin pasar por la fase cardiopulmonar. El estudio de estas diferencias nos puede proveer de nuevos conocimientos para enfrentar de mejor modo el problema.

\section{Diagnóstico de la infección humana por hantavirus}

Frente a la sospecha clínico-epidemiológica de infección aguda por hantavirus es necesario recurrir al diagnóstico específico realizado por el laboratorio que certifique o descarte la infección. El laboratorio debe disponer de tests sen- sibles y específicos, capaces de detectar precozmente la infección.

\section{Pruebas serológicas}

La manera más cotidiana de realizar diagnóstico de infección aguda es mediante la detección de IgM específica anti hantavirus. Al momento de plantearse la sospecha de infección, la mayoría de los pacientes ya presentan respuesta de IgM, o bien ésta se desarrolla a los pocos días después. Este diagnóstico precoz por IgM puede ser acompañado por la detección de IgG. La aparición de $\operatorname{IgG}$ específica ocurre pocos días después de la aparición de $\operatorname{IgM}$. La IgM puede acompañar al paciente convaleciente por al menos 6 a 8 meses, mientras que la $\mathrm{IgG}$ parece perdurar a niveles elevados durante varios años. ${ }^{19}$

Para la detección de IgM se prefiere la utilización de ensayos tipo ELISA de captura por ser altamente sensibles y específicos. No obstante, en toda prueba serológica hay que tener en consideración las características de los antígenos utilizados. A mayor homología antigénica con las variantes de una determinada área geográfica, mayor será la sensibilidad del test. En el cono sur de América parece haber cercanía antigénica entre las diferentes variantes o cepas circulantes (virus Andes, Laguna Negra, etc.). Esta relación es menos cercana con los virus Sin Nombre de Norteamérica o Puumala de Europa. Los virus asiáticos (por ejemplo Hantaan, Seuol) parecen ser claramente divergentes; por lo tanto, las pruebas serológicas que sólo contienen material antigénico de estos virus no son recomendadas para diagnóstico del SCPH.

\section{Detección viral}

Bajo ciertas circunstancias no es posible realizar el descarte o comprobación serológica de infección por hantavirus, ya sea por no disponer de la muestra apropiada o bien por estar frente a un paciente seronegativo que ha evolucionado rápidamente con resultado de muerte, en el cual podemos sospechar que la respuesta inmune humoral no se ha establecido aún. La opción es el diagnóstico directo ya sea mediante la detección del genoma viral, de proteínas virales (antígenos) o del virus propiamente tal. 


\section{Acidos nucleicos}

Una alternativa posible es la detección del ácido ribonucleico viral (ARN) ya sea en muestras de sangre (coágulo) u otros tejidos obtenidos en la autopsia (pulmón, hígado, riñón, bazo) utilizando la tecnología de transcriptasa reversareacción de polimerasa en cadena TR-RPC (RTPCR en su original anglosajón). Esta metodología es altamente sensible y específica para la detección de ácidos nucleicos virales, tanto en tejidos como en sangre $u$ otros fluidos de pacientes con infección aguda por hantavirus. ${ }^{20}$ En este tipo de muestras se realiza la extracción del contenido total de ARN y con este material ultra puro se realiza la prueba de TR-RPC, que consiste en la transcripción reversa (TR) específica del ARN blanco a cADN y luego la amplificación específica del cADN mediante ciclos térmicos con enzima ADN polimerasa (RPC). El producto final de estas reacciones es analizado mediante electroforesis en geles de agarosa o poliacrilamida. La presencia de banda de ADN en la posición esperada según el tamaño molecular y ausencia de ellas en los controles negativos, es indicativa de la presencia del ARN de hantavirus en el tejido examinado. La posibilidad de detección de ARN viral va disminuyendo en la medida que ocurre la eliminación de virus de los tejidos o de la sangre por parte del sistema inmune del huésped. Un frente de inconvenientes para la TR-RPC puede provenir de la posibilidad de mutaciones espontáneas del ARN blanco, o de estar frente a una variante genética que pueda involucrar cambios en la secuencia genética de ciertas posiciones claves para el reconocimiento por parte de los partidores (primers) propios de la prueba. Para diagnóstico se prefiere la selección de partidores complementarios a secuencias genéticas altamente conservada entre los diferentes hantavirus (por ejemplo, el segmento S que codifica para la nucleoproteína viral). ${ }^{9}$

\section{Antígenos virales}

Otra alternativa en uso para diagnóstico la constituye la detección de proteínas virales directamente en cortes de tejidos (técnicas de inmunohistoquímica). Mediante el uso de sueros hiperinmune anti hantavirus y los respectivos conjugados y sustratos se pueden visualizar los depósitos de proteínas virales especialmente asociados a las células endoteliales en tejidos fijados de los diferentes órganos, ya sea pulmón, hígado, bazo, etc. ${ }^{18}$

\section{Aislamiento viral}

Finalmente, otra alternativa para la detección de hantavirus puede ser el cultivo viral (o aislamiento viral) en células Vero E6. En la práctica, no constituye un procedimiento útil para muestras humanas dado el bajo rendimiento, demora en entregar resultados, necesidad de infraestructura (bioseguridad nivel 3) y recursos humanos adiestrados, etc. Sin embargo, para fines de investigación puede ser muy útil para en la obtención de cepas y su posterior caracterización. Una de las razones principales del bajo rendimiento en muestras humanas es que cuando se establece la sospecha de infección por hantavirus y se toman muestras, los pacientes ya presentan anticuerpos que neutralizan la capacidad infectiva de los viriones presentes en la muestra, inhibiendo su adherencia a la superficie de las células del frasco de cultivo. $^{21}$

\section{RESUMEN}

Los hantavirus son virus envueltos, de genoma ARN trisegmentado. Los hantavirus americanos provienen de la subfamilia de roedores Sigmodontinae y pueden causar el síndrome cardiopulmonar por hantavirus (SCPH) mientras que los hantavirus europeos y asiáticos provienen de las subfamilias Murinae y Arvicolinae que pueden producir la fiebre hemorrágica con síndrome renal. En este artículo se describen las técnicas de laboratorio desarrolladas al momento actual para certificar la infección por hantavirus en humanos.

\section{BIBLIOGRAFIA}

1.- WELLS R M, SOSA E S, YADON Z E et al. An unusual hantavirus outbreak in southern Argentina: person-to-person transmission? Emerg Infect Dis 1997; 3: 171-4.

2.- PADULA P J, EDELSTEIN A, MIGUEL S D L, LOPEZ N M, ROSSI C M, RABINOVICH R D. 
Hantavirus pulmonary syndrome (HPS) outbreak in Argentina: molecular evidences for person-to-person transmission of Andes virus. Virology 1998; 241: 323-30.

3.- ENRIA D, PADULA P, SEGURA E et al. Hantavirus Pulmonary Syndrome in Argentina: possibility of person to person transmission. Medicine 1996, 56: 709-11.

4.- TAPIA M. Síndrome Pulmonar por Hantavirus. Rev Chil Enf Respir 1997; 13: 103-10.

5.- TSAI T F. Hemorrhagic fever with renal syndrome: Mode of transmission to human. Lab Anim Sci 1987; 37: 428-30.

6.- FELDMANN H, SANCHEZ A, MORZUNOV S et al. Utilization of autopsy RNA for the synthesis of the nucleocapsid antigen of a newly recognized virus associated with hantavirus pulmonary syndrome. Virus Res 1993; 30: 351-67.

7.- HJELLE B, JENISON S, TORREZ-MARTINEZ N et al. A novel hantavirus associated with an outbreak of fatal respiratory disease in the southwestern United States: evolutionary relationships to known hantaviruses. J Virol 1994; 68: 592-6.

8.- DUCHIN J S, KOSTER F T, PETERS C J et al. Hantavirus pulmonary syndrome: a clinical description of 17 persons with a newly recognized disease. N Engl J Med 1994; 330: 949-55.

9.- NICHOL S, SPIROPOULOU C, MORZUNOV S et al. Genetic identification of a novel hantavirus associated with an outbreak of acute respiratory illness in the southwestern Unites States Science 1993; 262: 914-7.

10.- SCHMALJOHN C, HJELLE B. Hantavirus: a global problem. Emerg Infect Dis 1997; 3(2): 95-104.

11.- CHILDS J, BRYAN R. HPS in the Americas. In Manual of Hemorrhagic Fever with Renal Syndrome and Hantavirus Pulmonary Syndrome, 1999. WHO Collaborating Center for Virus Reference and Research, pp: 63-73.

12.- CHILDS J E, KSIAZEK T G, SPIROPOULOU C F et al. Serologic and genetic characterization of Peromyscus maniculatus as the primary rodent reservoir for a new hantavirus in the southwestern United States. J Infect Dis 1994; 169: 1271-80.

13.- LEVIS S C, MORZUNOV S P, ROWE J E et al. Genetic diversity and epidemiology of hantaviruses in Argentina. J Infect Dis 1998; 177: 529-38.

14.- LOPEZ N, PADULA P, ROSSI C, LAZARO M E, FRANZE-FERNANDEZ M T. Genetic identification of a new hantavirus causing severe pulmonary syndrome in Argentina. Virology 1996; 220: 223-6.

15.- LOPEZ N, PADULA P, ROSSI C et al. Genetic characterization and phylogeny of Andes virus and variants from Argentina and Chile. Virus Res 1997; 50: 77-84.

16.- ZAKI S R, GREER P W, COFFIELD L M et al. Hantavirus pulmonary syndrome: pathogenesis of an emerging infectious disease. Am J Pathol 1995; 146: 552-79.

17.- ZAKI S, KHAN A, GOODMAN R et al, Retrospective diagnosis of hantavirus pulmonary syndrome, 1978-1993. Arch Pathol Lab Med 1996; 120: 134-9

18.- ZAKI S. Nolte K. Pathology, Immunohistochemistry and in situ hybridization. In Manual of Hemorrhagic Fever with Renal Syndrome and Hantavirus Pulmonary Syndrome, 1999. WHO Collaborating Center for Virus Reference and Research, pp: 14254.

19.- ROSSI C A, KSIAZEK T G. Virus detection and identification with serological tests. In Manual of Hemorrhagic Fever with Renal Syndrome and Hantavirus Pulmonary Syndrome, 1999. WHO Collaborating Center for Virus Reference and Research, pp: 87-91.

20.- HJELLE B. Virus detection and identification with genetic test. In Manual of Hemorrhagic Fever with Renal Syndrome and Hantavirus Pulmonary Syndrome, 1999. WHO Collaborating Center for Virus Reference and Research, pp: 132-7.

21.- LEE H W. Virus isolation. In Manual of Hemorrhagic Fever with Renal Syndrome and Hantavirus Pulmonary Syndrome, 1999. WHO Collaborating Center for Virus Reference and Research, pp: 75-9.

Correspondencia a:

Héctor Galeno A.

Fax : 56 (2) 3507583

Email: hagaleno@yahoo.com 